\title{
A CIÊNCIA DAS ILHAS E OS ESTUDOS INSULARES: BREVES REFLEXÕES SOBRE O CONTRIBUTO DA GEOGRAFIA
}

\section{The science of islands and the insular studies: Brief point of view about the importance of Geography}

\author{
Paulo Espínola \\ Universidade de Coimbra, Coimbra, Portugal \\ geopespinola@hotmail.com \\ Fernanda Cravidão \\ Universidade de Coimbra, Coimbra, Portugal \\ cravidao@fl.uc.pt
}

Artigo recebido em 04/02/2014 e aceito para publicação em 31/07/2014

RESUMO: Ao longo das últimas décadas tem-se verificado um aumento do interesse pelos estudos insulares, atraindo investigadores de diversas áreas disciplinares que em conjunto tem sido capazes de promover esta "nova" linha de investigação. Tendo em conta a perspetiva internacional o presente texto pretende dar a conhecer as principais tendências ao nível da investigação sobre os espaços insulares, com particular destaque para a nova "ciência das ilhas". Partindo de uma análise retrospetiva recente sobre a evolução dos estudos insulares, o objetivo principal deste artigo passa por compreender a relação entre a Geografia (bem como dos geógrafos) e as ilhas, realçando o tipo de contributo que a ciência geográfica tem prestado a este tipo de análise territorial. Esta investigação inscreve-se num trabalho mais vasto no âmbito do doutoramento em Geografia que estamos a realizar.

Palavras-Chave: Ilhas; Ciência das Ilhas; Estudos Insulares; Geografia.

ABSTRACT: Throughout the last decades an increase in the interest for the island studies has occurred becoming appealing to researchers from different areas that together have been able to promote this "new" line of research. Considering the international perspective, this text intends to show the main tendencies of research on the island spaces with a particular prominence in the new "science of the islands". Growing from a recent retrospective analysis about the evolution of the island studies, the main objective of this article is to understand the relation between Geography (as well as geographers) and the islands highlighting the kind of contribute that Geography has been given to this type of territorial analysis. This research is included in a more vast work in the $\mathrm{PhD}$ in Geography that we are writing.

Keywords: Islands, Science of Islands; Insular Studies; Geography. 


\section{INTRODUÇÃO}

"O mundo está repleto de ilhas" (BALDACCHINO, 2006b, p. 4)! Se assim é, por que razão não estudá-las? Será que não têm nada para oferecer no sentido de serem investigadas?

A ciência das ilhas, embora jovem, tem revelado grande interesse nos estudos internacionais, como é demonstrado pelo título do editorial da revista Tijdschrift voor Economische en Sociale Geografie: "A chegada da Era dos estudos insulares" (BALDACCHINO, 2004), proclamando deste modo a "maturidade" dos estudos insulares (KING, 2010).

Os espaços insulares sempre foram alvo de interesse em termos de investigação. As pequenas ilhas desde há muito que despertam sentimentos opostos, por vezes ambíguos, tanto na população residente como também entre os seus diversos tipos de visitantes. O facto de serem territórios diminutos totalmente rodeados por água, cuja localização poderá encontrar-se a grande distância de outras áreas emersas, pode provocar emoções contraditórias entre os diferentes tipos de atores dos espaços insulares. O surgimento de uma sensação de "insulafobia", que exprime o medo (exagerado) pelas ilhas, enquanto espaços demasiado limitados e excessivamente fechados/isolados, poderá ser uma consequência. Todavia, por vezes sucedem-se situações próximas do conceito de "insulafilia", sentimento que expressa a adoração pelas ilhas (de forma exagerada), que segundo King (2010: 31) "consiste em visitar tantas ilhas quanto possível". No entanto, estes dois tipos de estados mentais constituem geralmente exceções ao nível da relação Homem-ilha. Com efeito, a maioria da população insular cria laços afetivos com a sua terra natal, tal como acontece com os habitantes de qualquer outro território continental, sendo até por vezes mais intensos devido ao próprio fator de insularidade, comprovando-se deste modo a natural adaptação às condições oferecidas pelo meio. Mesmo para os que mudam a sua residência para zonas continentais, a relação com o ambiente insular nem sempre se deteriora, podendo até ser reforçado. Por sua vez, para os que simplesmente estão de passagem pelos territórios insulares, fazem-no não por adorarem persistentemente as ilhas, mas porque aqueles espaços garantem uma alternativa diferenciada de curta duração, que possibilita a evasão à rotina diária dessa gente.

Habitualmente às ilhas é associada a ideia de vulnerabilidade (no sentido de "fraqueza" e permanente dependência), no entanto persistem exemplos de grande sucesso, como por exemplo o império construído a partir da (ilha da) Grã-Bretanha, ou então, a expansão territorial edificada durante a Segunda Grande Guerra mundial pelo arquipélago japonês. Aliás, neste âmbito, torna-se conveniente recordar que a "condição insular" constituiu-se como um dos fatores decisivos que contribuiu para a forte resistência demonstrada pela população britânica à enorme ameaça nazi, naquela fase da história mundial. Com os exemplos apresentados, não desejamos ocultar as debilidades típicas com que as pequenas ilhas estão diariamente confrontadas, todavia pretendemos refutar uma visão que defende um "determinismo negativista" para os espaços insulares, uma vez que mediante contextos relacionados com a dimensão e a qualidade dos seus territórios (e populações) é possível, também, identificar nas ilhas sociedades vanguardistas.

Suportado por uma pesquisa realizada em revistas e livros nacionais e estrangeiros sobre ilhas, este artigo cumpre vários objetivos que procuram promover o interesse pelo desenvolvimento da área de estudos em destaque: demonstrar as principais evoluções registadas ao nível dos estudos insulares; definir as tendências dominantes ao nível da investigação sobre ilhas; e realçar a importância da Geografia, e dos geógrafos, na consolidação dos conhecimentos (académicos) nesta área do saber. A organização do texto encontra-se em conformidade com os objetivos estipulados, daí apresentar três capítulos principais.

\section{A "CIÊNCIA DAS ILHAS" E OS ESTUDOS IN- SULARES: BREVE SÍNTESE EVOLUTIVA}

\author{
"Let me propose that the next millennium is to \\ be the Island Millennium, a nissological mil- \\ lennium, when the custodians of the planet and \\ its resources shall be islanders." (McCALL, \\ 1996, p. 84)
}

Em 2004, por altura do anúncio da "Era dos estudos insulares", Godfrey Baldacchino salientou 
que o número de publicações sobre as ilhas estava a aumentar rapidamente em todas as áreas disciplinares, sendo este um dos motivos apontados para a "maturação" dos estudos sobre espaços insulares. No entanto, para que tal tenha ocorrido foi necessário verificar-se alterações ao nível das estruturas de apoio a este tipo de investigação, através das quais despontou uma "ciência das ilhas" que naturalmente é considerada por nós um marco fundamental na consolidação de uma linha de investigação direcionada para o estudo específico das regiões insulares.

\section{A evolução das estruturas de apoio aos estudos insu- lares}

Ao longo da História sempre foram surgindo textos relacionados com os espaços insulares, associados a diferentes géneros literários, desde tempos mais remotos. Relativamente às ilhas atlânticas, Orlando Ribeiro (1960, p. 19) refere que "a lenda das Ilhas Afortunadas criou-se na Antiguidade, quando a imaginação dos homens procurava, num lugar perdido e distante, um mundo melhor que este onde viviam." Segundo este mesmo autor, foi a partir desta lenda que Platão redigiu a descrição mítica da Atlântica: "onde os homens viviam numa felicidade perpétua, na paz, na prosperidade e na justiça" (Idem). É com esta perspetiva excessivamente positiva sobre os espaços insulares, que Thomas More publica pela primeira vez em 1516 a obra "Utopia", a qual representa uma ilha (imaginária) habitada por uma sociedade perfeita. Nesse mesmo século, o português Luís de Camões inclui nos "Lusíadas" o mito da "Ilha dos Amores", prestando assim um contributo nacional ao papel idílico dos espaços insulares. Nesta perspetiva, as ilhas são como que um "espaço-solução" para os problemas existentes nas sociedades (continentais) da época.

Outras publicações foram surgindo desde então, todavia algumas das mais bem-sucedidas apresentaram-se com um carácter mais ligado à ficção literária, como o romance (da ilha) de Robinson Crusoe, de Daniel Defoe (1719). Não obstante, os marcantes estudos desenvolvidos no século XIX por Charles Darwin (ilhas Galápagos) e Alfred Wallace (arquipélago indonésio) constituíram-se como grandes referências na explicação da evolução da vida natural na Terra, colocando assim as ilhas numa posição central para entender o desenvolvimento da ciência. Porém, foi durante o século XX que se verificou a consolidação deste novo ramo científico (sobre ilhas). Pois, para se desenvolver estudos insulares de uma forma sistemática e consolidada foi necessário criar uma série de instituições e organizações de carácter nacional e internacional cuja preocupação principal se centrasse na promoção de estudos sobre territórios insulares. Normalmente torna-se difícil desenvolver estudos numa área do saber com elevado rigor científico, sem que a investigação coabite com instituições de ensino superior/Universidades. Neste âmbito, segundo McCall (1994) o "Center for Pacific Islands Studies" (Universidade do Hawai) foi um dos primeiros a ser fundado, em 1950. No entanto, segundo este autor, a primeira instituição a dedicar-se ao estudo das ilhas em geral foi o "Institute of Islands Studies", fundado em 1985 na Universidade de Prince Edward Island (Canadá), onde "a partir de 2003 foi instalado o primeiro centro de pesquisa das ilhas do mundo académico" (BALDACCHINO, 2006c). No entanto, cada vez é mais frequente encontrar Universidades com institutos e/ou centros de pesquisa próprios especializados nos vários temas das ilhas. Russel King (2010, p. 35) refere que "uma das justificações para a "maturidade" dos estudos insulares enquanto disciplina reconhecida é a existência, desde há algum tempo, de dois programas de mestrado (na Universidade de Prince Edward Island e na Universidade de Malta) e de duas revistas cientificas dedicadas ao tema: a Island Studies Journal, publicada desde 2006 e cujos artigos são objeto de peer-review; e a mais antiga (desde 1992) mas menos académica Insula, publicada com o apoio da UNESCO.” Com efeito, constata-se que para uma nova área disciplinar se afirme no mundo atual, torna-se necessário que obtenha sucesso em termos académicos, nomeadamente ao nível dos estudos pós-graduados, como é o caso do exemplo utilizado anteriormente.

Do mesmo modo, algumas das associações internacionais não académicas, quer de âmbito governamental quer não-governamental, também desempenharam um papel extremamente importante ao nível das reuniões científicas e na publicação de estudos sobre ilhas, na medida em que forneceram apoios de ordem logística e material para o efeito. Embora não seja objetivo enumerar todo o tipo de organizações envolvidas, pretendemos destacar as 
Nações Unidas, que tem participado de forma ativa na promoção de iniciativas em, e sobre, ilhas, sendo responsável pelo surgimento da AOSIS ("Alliance of Small Islands States") em 1992, e que segundo McCall (1994, p.101) "é a representação política do crescente interesse na Nissologia", outros exemplos podem ser apontados através das suas agências, como a UNES$\mathrm{CO}$, que contribuiu para a formação da organização não-governamental "International Scientific Council for Islands Development", cooperando com a mesma na publicação da revista Insula, já mencionada neste texto. O próprio Banco Mundial possui um fórum dedicado aos pequenos Estados, onde estão incluídos os pequenos Estados insulares. De salientar ainda a associação ISISA ("International Small Islands Studies Association") que é responsável pela organização de conferências bienais sobre pequenas ilhas, desde 1992.

Outra constatação que resulta da nossa observação sobre estudos insulares está relacionada com a origem dos principais investigadores desta temática. Notamos que a grande maioria destes cientistas são oriundos de países-ilhas/arquipélagos, Estados que possuem territórios insulares ou até mesmo aqueles que possuem uma relação histórica com este tipo particular de espaços, por exemplo, através de um passado colonial de dependência. Por conseguinte, os principais centros de investigação que reúnem estudiosos especializados em ilhas estão localizados em países como o Reino Unido, República da Irlanda, Itália, França, Canadá, Austrália, Nova Zelândia, etc. Por outro lado, após a Segunda Guerra Mundial, e principalmente a partir dos anos (19) 60, verificou-se um aumento do número de Estados-Insulares independentes que, a par de alguma ajuda internacional, foram capazes de montar os seus próprios centros de investigação sobre pesquisa insular. A este nível, é de salientar a constituição da "University of the South Pacific", cujas estruturas estão distribuídas por vários países insulares daquela área do globo, incluindo uma original "Faculty of Islands and Oceans". Assim, ao longo das últimas décadas tem-se assistido a uma multiplicação dos centros de investigação, de cientistas e de associações internacionais que têm como preocupação essencial os espaços insulares. Daí Baldacchino (2006c, p. 7) referir que "o estudo das ilhas nos seus próprios termos goza atualmente de um crescente e abrangente reconhecimento".

\section{A "ciência das ilhas": em busca da terminologia correta}

No início dos anos 1980, Abraham Moles publicou um artigo na revista $L^{` E s p a c e ~ G e ́ o g r a p h i q u e ~}$ intitulado "Nissonologie ou science des îles". Esta publicação proporcionava assim uma nova discussão em torno dos estudos insulares, uma vez que a partir de então era possível falar de uma ciência própria das ilhas, enquanto área autónoma do saber. A este respeito, Bonnemaison (1990-1991) considerou que a análise efetuada por Moles possui um carácter mais psicológico do que geográfico, apelando ao aprofundamento deste tipo de abordagem. Neste seguimento, um outro autor francês, "Depraetere (1990-1991; 1992), emprega pela primeira vez o termo "Nissologie" em francês" (McCall, 1994, p. 103). Não levaria muito mais tempo para que a designação desta nova ciência surgisse também na língua inglesa, cabendo esta responsabilidade ao australiano Grant McCall, que através de um artigo publicado em 1994 propôs o vocábulo "Nissology" para designar a ciência das ilhas, atribuindo-lhe uma breve definição: "o estudo científico das ilhas, segundo os seus próprios termos". McCall (1994) justifica o termo "Nissology" tendo por base a junção de dois vocábulos provenientes do grego antigo: "nisos" (ilha) e "logos" (estudo de). Expandiu-se deste modo o debate sobre a nova ciência na literatura anglo-saxónica, no qual vão surgir críticas à perspetiva apresentada por McCall (que retomaremos mais à frente). No entanto, a evolução sobre a terminologia desta ciência não acaba aqui. Em 2010, um português, Alberto Vieira, reabre o debate sobre a sua designação, que tinha sido originalmente traduzida para português como Nissologia. Baseando-se nas ideias de um especialista em estudos clássicos, Marcos Martinez, propõe a sua substituição por Nesologia. Para o especialista referido por Vieira, existe uma possível confusão entre a forma de escrita (grafia) e a fonética das palavras com origem no grego antigo, alegando que a palavra ilha referente ao grego clássico é "nesos", mas que os modernos dizem "nissos", em virtude do fenómeno do itacismo, ou seja, pronunciar a vogal antiga por uma vogal moderna. 
Partilhamos da ideia de Vieira (2010, p. 20), ao referir que "são múltiplas as formas como tem sido substantivada esta nova ciência das ilhas", no entanto, acreditamos que esta ciência veio para ficar e que face à sua atual fase de consolidação torna-se muito difícil refutá-la. Neste sentido, convém destacar que ainda não estão reunidas as condições necessárias para revelarmos a nossa posição final sobre o termo correto da "ciência das ilhas", mas é nosso objetivo aprofundar esta questão, para tal pretendemos solicitar o auxílio de outros especialistas, a fim de se chegar a uma realidade o mais objetiva possível.

Não obstante considerarmos importante a questão terminológica, julgamos que esta não é fundamental para suster a "ciência das ilhas", até porque a realidade demonstra que existem cada vez mais cientistas atraídos pelos estudos insulares, o que tem permitido ampliar os domínios ao nível da investigação sobre esta nova área do saber, assunto que será abordado em seguida.

\section{A IMPORTÂNCIA CIENTÍFICA DAS ILHAS: PRINCIPAIS TENDÊNCIAS AO NÍVEL DA IN- VESTIGAÇÃO}

\begin{abstract}
Throughout human history, islands have held a special place in the minds, the imaginations, the affections of mankind. What are the special secrets of their charm? The remoteness of islands surrounds them with a certain mystery, and their isolation is responsible for their individual characteristics and evolutionary history (YOUNG, 1999, p. 2).
\end{abstract}

Todas as terras emersas, de maior ou menor dimensão, estão rodeadas por oceanos, pelo que as ilhas ocupam, inevitavelmente, um lugar de extrema importância na vida mundial (BIAGINI; HOYLE, 1999, p. 1). Há factos que traduzem de uma forma sintética o real valor das ilhas a nível mundial, embora os mesmos sejam frequentemente ignorados pela maioria dos investigadores. Segundo Baldacchino (2007), perto de $10 \%$ da população mundial (quase 600 milhões de pessoas) vivem atualmente em ilhas, ocupando cerca de $7 \%$ da superfície da Terra. Aproximadamente um quarto dos Estados independentes do mundo são ilhas ou arquipélagos. Para além disso, as ilhas assumem-se como identidades e espaços diferenciados num mundo cada vez mais homogéneo (em resultado do processo de globalização).

Apesar da sua relevância, os pequenos espaços insulares encontram-se frequentemente associados a um conjunto de constrangimentos estruturais, uma vez que "em consequência da sua escala, as pequenas ilhas são limitadas em tamanho, em área de terra, em recursos, em potencial económico e populacional, e poder político (ROYLE, 2001, p. 42). Assim, não surpreende que da totalidade de países soberanos não inteiramente insulares, somente dois apresentam a sua capital numa ilha, sendo estes a Dinamarca e a Guiné Equatorial, traduzindo uma preferência político-funcional pelas áreas continentais em detrimento dos territórios exclusivamente rodeados por água.

No entanto, "os supostos riscos de pobreza e vulnerabilidade económica dos habitantes das ilhas são postos em causa pelo facto do PIB per capita dos Estados insulares ser em geral superior à média mundial, de tal forma que os pequenos Estados insulares se encontram sobre-representados entre os países de rendimento médio e elevado (KING, 2010, citando READ, 2004). Com efeito, devemos ter em atenção a escala de análise, até porque "o que parece ser uma evidência é o facto de todas as ilhas serem únicas" (BALDACCHINO, 2004, p. 278), e nas quais estão presentes condições físico-humanas particulares que mediante as especificidades do contexto insular em que se inserem podem produzir efeitos diversos ao nível dos problemas estruturais que afetam as ilhas. Por outro lado, numa perspetiva de transformar as fraquezas em forças, Royle (2001) afirma que os dois fatores que tornam as ilhas tão especiais são precisamente o isolamento e o facto de se apresentarem como espaços limitados. Talvez por isso, às ilhas é frequente serem associados cenários idílicos, uma vez que podem ser considerados "locais com uma poética especial" (BACHELARD, 1957, apud HENRIQUES, 2009, p. 13).

Deste modo, são muitas as dificuldades e potencialidades que podemos encontrar nas ilhas, por isso estes espaços possuem uma enorme riqueza ao nível do estudo científico. Lockard e Drakakis-Smith (1997) referem que os temas das ilhas que mais tem 
atraído a atração dos investigadores inclui, para além da atividade turística, a emigração e migração de retorno, transportes e acessibilidade, recursos limitados (como o abastecimento de água) e políticas de desenvolvimento económico.

Em 1993, King atribuiu às ilhas dois papéis históricos contrastantes, o de isolamento e o facto de terem funcionado como "centros de encontro e fusão dos povos". Com efeito, o facto de se tratar de territórios com elevado grau de isolamento, principalmente no caso das ilhas "profundamente" oceânicas, possibilitou a formação de formas culturais-identitárias distintas, bem como a conservação de modos de vida não humana mais primitivas (veja-se, por exemplo, a fauna e a flora das ilhas Galápagos e da maior ilha africana, Madagáscar). Por outro lado, as ilhas foram alvo de uma multiplicidade de movimentos migratórios, desde uma primeira fase de imigração resultante do povoamento inicial, a uma intensa relação com a emigração e migrações de retorno, a novos tipos de imigração. As ilhas, pela sua posição marítima, foram muitas vezes pontos estratégicos utilizados na expansão dos diversos impérios da época dos descobrimentos, pelo que permitiram a coabitação de povos muito diferentes.

Num trabalho mais recente (2010), o mesmo autor refere que atualmente existem três perspetivas ao nível da investigação sobre estudos insulares: uma relacionada com a "Nissologia" de McCall (1994, 1996), outra assente na noção de insularidade (Baldacchino, 2004), e, uma terceira, relacionada com o facto de as ilhas se constituírem como laboratórios espaciais.

A abordagem proposta por McCall (1994, 1996) tem sido alvo de uma crítica principal, partilhada por alguns dos autores da área (BALDACCHINO, 2008; KING, 2010), na medida em que "McCall privilegia a perspetiva subjetiva dos habitantes locais, por oposição à suposta objetividade dos investigadores externos" (KING, 2010: 32). Dando primazia aos estudos realizados por insulares sobre os seus próprios espaços de naturalidade/residência, há sempre o risco de a investigação produzida poder estar enviesada. Assim, existe a possibilidade dos investigadores locais imprimirem nos seus trabalhos perceções já previamente adquiridas, relacionadas, por exemplo, com conotações persistentemente positivas ou negativas referentes ao contexto insular em que se inserem. Estamos em crer que o perfil dos investigadores não deverá excluir nem incluir totalmente os investigadores de um determinado local, julgamos que o sucesso dos estudos insulares passa pela formação de equipas multidisciplinares cuja origem dos cientistas poderá ser multiterritorial (como por exemplo, conjuntos que simultaneamente integram insulares e não insulares). Até porque, num mundo com o atual grau de globalização torna-se difícil traçar a fronteira entre locais e não locais. Por outro lado, King (2010) critica a expressão final utilizada na definição de Nissologia de McCall, "nos seus próprios termos", na medida em que transmite uma ideia de homogeneidade e unanimidade nas comunidades insulares, o que não se verifica em resultado das diferenças ao nível da classe social, da etnia ou do percurso migratório dos vários elementos que pertencem às sociedades insulares.

Numa perspetiva dos estudos insulares que apresenta como referência o conceito de insularidade, Baldacchino (2004) alerta para o perigo tradicional que existe sobre o negativismo associado a esta noção, pois conforme destaca Henriques (2009, p. 13/14) "entre essas "certezas" que costumamos aceitar como categóricas ou definitivas sobre ilhas e a condição insular estão ideias como as de isolamento e solidão, de separação e afastamento, de fechamento e de aprisionamento." Ora, nem sempre este tipo de visão corresponde à realidade, até porque o conceito de insularidade deverá ser considerado com alguma relatividade. De acordo com Biagini e Hoyle (1999) o conceito de insularidade está muito longe de ser fácil definir, tratando-se de uma ideia problemática. A este respeito, Marshall (1999) sugere que a noção de insularidade não é apenas um conceito geográfico, mas também, e objetivamente, um estado de espirito. É frequente introduzir-se a questão mental como complemento da realidade geográfica, pois trata-se de um espaço rodeado por uma determinada massa de água que psicologicamente não produz o mesmo efeito sobre todos indivíduos, uma vez que o sentimento insular varia de pessoa para pessoa. Com efeito, "peguemos" num exemplo extremo, o de uma ilha deserta. Para uns essa ilha será certamente uma prisão, uma situação de isolamento, distância, abandono, mas para outros pode constituir a única forma 
de liberdade total, no sentido em que não estão a ser condicionados por nenhum outro membro social. A este respeito, sabe-se que durante a história certas ilhas foram destino para condenados, no entanto, são conhecidos exemplos de indivíduos abastados que compram ilhas desertas para gozarem férias sozinhos ou apenas acompanhados com familiares e/ou amigos (de total confiança!).

Subjacente à ideia de insularidade está naturalmente o conceito de ilha. Aliás, consideramos que são os dois conceitos centrais quando falamos de estudos insulares, pelo que convém procurar previamente compreender estas noções, no sentido em que se torna mais simples e eficaz adequar pesquisas neste âmbito. Daí acharmos necessário fazer considerações nesta parte do trabalho sobre a noção de ilha, numa perspetiva relacionada com o seu isolamento que pode ser alterado, perspetivando-se assim mudanças ao nível da insularidade. O dicionário de língua portuguesa da Porto Editora (2011) apresenta duas definições para a palavra ilha, a primeira surge na linha tradicional, "porção de terra cercada de água por todos os lados", enquanto a segunda refere "aquilo que está isolado". De facto, é frequente identificar uma ilha como sinónimo de isolamento. Porém, tal não significa que certas ilhas estejam mais isoladas que outros territórios continentais, pois se possuírem uma localização muito próxima das margens dos continentes, podem apresentar interligações mais favoráveis com uma zona litoral desenvolvida em comparação com áreas interiores situadas a uma distância maior e com comunicações mais irregulares. Além do mais, a proximidade de um território insular da costa dos continentes poderá permitir a construção de uma forma de comunicação fixa (pontes ou túneis) ao espaço continental adjacente. Embora por esta via se verifique uma intensa diminuição do isolamento, Baum (1996, p. 24) considera que "uma ligação artificial terrestre retira a perfeição da ilha", por vezes esta perspetiva é levada tanto a sério que "para o EUROSTAT, por exemplo, as "ilhas" ligadas ao continente por pontes ou túneis não são incluídas nas estatísticas dos territórios insulares (não são consideradas "ilhas", portanto)" (HENRIQUES, 2009, p. 21). Por este motivo, não se pode colocar as ilhas numa posição periférica permanente, pois há exemplos de territó- rios insulares que se constituem como nós centrais de um mundo atual globalizado.

Por fim, temos uma terceira visão em que as ilhas são "utilizadas" como laboratórios espaciais: "as ilhas são lugares de testes, e não somente para planos económicos ou para armas nucleares" (BALDACCHINO, 2004, p. 278). De facto, "as ilhas têm, desde há muito, sido utilizadas de forma produtiva enquanto contexto semi-laboratorial para o estudo de processos ecológicos, epidemiológicos e sociais" (CONNEL; KING, 1999; KING, 1999; KING, 2010). No entanto, Russel King, embora reconhecendo este importante papel das ilhas, alerta para os perigos inerentes a este tipo de visão dos estudos insulares, nomeadamente o facto de estes espaços poderem ser vistos como sistemas fechados, ou como réplicas em miniatura dos continentes ou do planeta. As ilhas podem ser consideradas pequenos mundos? Poderão refletir o todo global?

Pelo que ficou descrito, podemos afirmar que não faltam razões para estudar as ilhas. Independentemente da perspetiva utilizada, a investigação sobre espaços insulares revela uma grande amplitude temática, dado que podem ser analisados de diferentes ângulos. O texto até agora produzido engloba muitas citações pertencentes a geógrafos. A razão pela qual tal se verificou não está relacionada com a nossa preferência por este tipo de cientistas, embora sejamos também geógrafos, mas pelo facto de serem incontornáveis nos estudos internacionais sobre ilhas. Por conseguinte, torna-se importante especificar o papel da Geografia e dos geógrafos nos estudos insulares, aspeto que trataremos a seguir.

\section{A GEOGRAFIA E OS ESTUDOS INSULARES}

Islands have long attracted the attention of geographers and researchers in cognate disciplines and, moreover, research has been spread over a range of economic, environmental and social issues (LOCKHART, 1993, p. 1).

\section{A atuação do(s) "Geógrafo(s) das Ilhas"}

"A ilha é um objeto geográfico" (GOMBAUD, 2010, p. 51). Para este autor "um geógrafo pode espe- 
cializar-se no estudo das ilhas" (p.52), o que significa "estudar os espaços insulares, as ilhas e os arquipélagos". No entanto, o "geógrafo das ilhas" traduz um tipo de especialização que apresenta como referência um espaço com características muito particulares, não incidindo em concreto, e de forma individualizada, num determinado ramo da geografia humana (como a geografia da população, geografia social, geografia económica, etc.) ou da geografia física (tal como a geomorfologia, a climatologia, a hidrologia, etc.). Por conseguinte, o campo de análise de um "geógrafo das ilhas" corre o risco de ser demasiado abrangente, embora seja observado um espaço (ou um conjunto de espaços) rigorosamente limitado, e, por vezes, de reduzida dimensão. Por outro lado, não é de todo comum falar-se em "geógrafos dos continentes", logo poderá ser questionado o facto de ser necessário uma especialização particular ao nível das ilhas.

Não obstante das principais críticas/dúvidas acerca do "geógrafo das ilhas", a ciência geográfica não pode renunciar ao seu papel no desenvolvimento dos estudos insulares. Aliás, assiste-se cada vez mais a um estreitar da relação entre a geografia e as ilhas, como pode ser personificado por um poema intitulado "Geografia", elaborado pela geógrafa portuguesa Fátima Velez de Castro, que caracteriza metaforicamente esta ciência como uma ilha:

\section{GEOGRAFIA}

\section{Melancolia}

de ser uma ilha

de nascer de um rift num qualquer oceano

\section{E conhecer todos os navegadores \\ que ao chegar tocam \\ nesta rocha que me sustenta. (...)}

(VELEZ DE CASTRO, 2012, p.83)

Há muito que as ilhas atraem as atenções dos geógrafos (KING, 1993). Este autor destaca o especial contributo dos geógrafos no início do século XX, como Ellen Churchill Semple, Jean Brunhes e Paul Vidal de la Blanche, e mais tarde, Fernand Braudel, por terem salientado o importante papel das ilhas em alguns dos seus trabalhos principais. No entanto, "numa fase posterior do século XX, as ilhas passaram de moda enquanto objeto de estudo" (KING, 2010, p. 29). Este desinteresse da geografia e da investigação geográfica pelas ilhas foi motivado por um conjunto de razões, dos quais King (2010) destaca cinco principais:

- as ilhas são sinónimo de férias, descontração e diversão, não de trabalho cientifico sério;

- as dimensões reduzidas da maior parte das ilhas estão associadas à ideia de insignificância;

- o estudo das ilhas invoca um olhar académico de tipo colonial, em que o "especialista" olha de fora para dentro;

- o equívoco que consiste em encarar as ilhas como pequenos "modelos" à escala do mundo;

- o risco do excecionalismo - considerar-se que as ilhas são demasiado especiais, demasiado únicas.

No entanto, parece-nos que um movimento recente constituído por uma nova geração de geógrafos tem conseguido contornar este tipo de problemas com algum sucesso, ao procurarem aprofundar a investigação sobre estudos insulares. Neste contexto, McCall (1994, p. 105) atribui aos geógrafos franceses a responsabilidade de terem iniciado o desenvolvimento do conceito de "Nissology" (MOLES, 1982; DEPRAETERE, 1990-91). Com efeito, a geografia está na génese de um dos principais temas em discussão nos estudos insulares da atualidade. Mas, a cooperação dos geógrafos não fica por aqui, comunidades de geógrafos internacionais tem prestado um contributo fundamental para o desenvolvimento dos estudos insulares, seja através de reuniões científicas (por exemplo, "The Commonwealth Geographical Bureau Conference on Small Island Development", Malta, em março de 1990), como também na produção de trabalhos de pesquisa publicados (por exemplo, serem editores da coleção "Islands Studies Series"). Esta preocupação da ciência geográfica é reforçada pelo facto da própria União Geográfica Internacional possuir uma comissão própria sobre ilhas. Por outro lado, numa das obras (consideradas por nós) mais completas, e recentes, sobre pequenas ilhas, em termos temáticos transversais, "The World of Islands", 
cuja edição foi dirigida por Godfrey Baldacchino (2007), os geógrafos assumiram-se como o grupo de cientistas maioritário em termos de publicação. Tratando-se de uma edição transversal, e dirigida por um não geógrafo, não deixa de ser relevante que dos 28 autores que contribuíram com capítulos para o livro, 11 são geógrafos, o que corresponde a cerca de $39 \%$ do total dos investigadores, atestando bem o interesse e o reconhecido papel da geografia para os estudos insulares.

Portanto, deparamo-nos com alguns factos que nos permitem sugerir que a geografia tem sido uma das áreas disciplinares que mais tem procurado desenvolver os estudos insulares. Daí julgarmos importante salientar já de seguida os principais conteúdos insulares que se enquadram no perfil dos geógrafos.

\section{Perspetivas sobre as principais áreas temáticas in- sulares dos geógrafos}

O papel dos geógrafos pode sair extremamente valorizado quando estes se dedicam ao estudo das ilhas, nomeadamente se tiverem em conta a resolução de determinados problemas associados ao contexto insular, mas também há outros aspetos da insularidade que devem integrar a lista de preocupações do geógrafo, e que pretendemos expor neste espaço, segundo a nossa visão.

Relativamente aos dois conceitos, que já os consideramos como centrais dos estudos insulares, insularidade e ilha, entendemos que são da responsabilidade dos "cientistas do território", principalmente em relação ao que foi mencionado em último lugar. A clássica definição de ilha, "porção de terra rodeada por água por todos os lados", está longe de ser consensual entre os investigadores atuais. Na realidade, a grande problemática está relacionada com os seus limites, tanto o seu máximo como o mínimo, pois a ausência de um intervalo universalmente aceite, por vezes, cria dificuldades ao nível da sua distinção com outros territórios também rodeados totalmente por água, como o ilhéu ou o continente. É consensual a ideia que as ilhas situam-se entre estes dois últimos conceitos geográficos, mas quando termina um e começa o outro? A Gronelândia é geralmente aceite como a maior ilha do mundo, no entanto, quando se discute o território insular da Austrália a dúvida levanta-se sempre: trata-se de uma ilha ou de um continente? Quais os critérios que deverão ser utilizados numa definição deste tipo? Deverão ser somente naturais? Ou então, devemos também ter em conta aspetos humanos e/ou socio-emocionais?

O geógrafo é naturalmente um dos vários cientistas a quem cabe refletir sobre os temas territoriais das ilhas, como por exemplo a definição de ilha ou a construção de tipologias de espaços insulares, preocupações geralmente presentes, por exemplo, nos trabalhos do geógrafo Stephen Royle (2001, 2007). De forma igualmente meritória e inovadora, destaque para Christian Depraetere, um dos fundadores da "Nissologie", que tem procurado desenvolver modelos que facilitem a classificação dos vários espaços insulares (Depraetere, 1990-1991; Depraetere e Dahl, 2007), em consequência da sua formação em "hidrogeomorfologia". Assim, o geógrafo apresenta o perfil mais adequado para localizar, definir, classificar e tipificar ilhas.

Em 1993, King apresentou as 3 fases que, segundo o mesmo, constituem o ciclo da paisagem das ilhas mediterrâneas: a primeira, caracterizada por um espaço limitado com elevada densidade populacional e um sector agrícola com um avançado grau de organização; a segunda refere-se ao declínio da paisagem anterior e ao abandono dos campos, em resultado da emigração e de outros fatores; por fim, a terceira fase é marcada pelo crescimento da atividade turística. Julgamos que existe todo o interesse em aprofundar este tipo de ciclo de paisagem insular, reconstruindo-o, com a possibilidade de eliminar ou acrescer novas fases. Este modelo poderá ser aplicado a outras regiões insulares, sendo que o geógrafo ao verificar que não se ajusta à região em análise, deverá desenvolver novas propostas adequadas ao nível de evolução das paisagens das ilhas.

Os geógrafos também podem, e devem, atuar no desenvolvimento dos espaços insulares, particularmente ao nível do planeamento territorial e da questão ambiental. No entanto, muitas vezes o que "aflige" as pequenas regiões insulares está relacionado com a vertente socioeconómica das suas populações. Por conseguinte, um cientista, como o "geógrafo das ilhas", que estude este tipo de regiões insulares 
deverá procurar que o seu trabalho de investigação contribua para desenvolver as ilhas, numa perspetiva de melhorar o bem-estar das respetivas sociedades. Neste contexto, as (tele)comunicações são a chave-central para a quebra de isolamento e consequente aumento do contacto entre as ilhas e o resto do mundo. A procura de um crescimento económico sustentado, e sustentável, no sentido em que se procure diminuir a dependência exterior das ilhas, sem se verificar perda de qualidade de vida, é outro aspeto fundamental. Ora, uma pequena ilha (ou conjunto de pequenas ilhas) não tem de ser obrigatoriamente vulneráveis a forças exteriores, podendo, na maioria dos casos, optar pelo seu próprio modelo de desenvolvimento. Neste âmbito, nas duas últimas décadas tem surgido um grande debate sobre dois tipos de modelos de desenvolvimento aplicados a pequenos Estados insulares: MIRAB (BERTRAM; WATTERS, 1985) e PROFIT (BALDACCHINO, 2006a, 2010), enquanto o primeiro assenta num sistema em que o grau de dependência do exterior é extremamente elevado (fundamentalmente através de remessas de emigrantes e ajuda ao desenvolvimento), o segundo, mais recente, propõe um aproveitamento dos recursos endógenos insulares, como a rentabilização da própria população interna, dos recursos naturais (por exemplo, aplicados à atividade turística) ou através da constituição de zonas francas ("offshore"), atraindo assim capital de grandes empresas mundiais. Estes modelos surgiram para contrariar os obstáculos estruturais que condicionam os pequenos territórios insulares. Neste sentido, as grandes dificuldades das pequenas regiões insulares está relacionada com a limitação do seu território e os reduzidos quantitativos populacionais que habitam nesses espaços. Por um lado, ter pouco território implica uma reduzida extensão de solo agrícola, o que certamente provoca problemas ao nível da quantidade e variedade das culturas agrícolas, revelando-se também insuficiente em matérias-primas para sustentar as diversas atividades associadas ao sector industrial. Por outro lado, uma diminuta dimensão demográfica não permite a formação de uma massa crítica capaz de sustentar um tecido empresarial privado consistente, e de pagar impostos a um nível que possibilite ao sector público realizar investimentos com qualidade em áreas como os transportes, saúde ou a educação.
Porém, estes problemas podem ser esbatidos, uma vez que a produção industrial deve assentar nas matérias-primas disponíveis nas ilhas, como por exemplo, nos provenientes da agropecuária e/ou da pesca. Aliás, os recursos piscícolas podem ser abundantes em qualquer ilha, uma vez que é rodeada por água, embora nem sempre se verifique. O recurso mar tem de ser encarado no desenvolvimento das ilhas, seja através da pesca, como da produção de energia elétrica, ou então, quando a temperatura das águas permite, no turismo balnear. É com base nesta última atividade económica que muitos Estados insulares têm prosperado rapidamente, de tal forma que McElroy (2006) e McElroy e Hamma (2010) propuseram um terceiro modelo de desenvolvimento insular, SITE ("Small Islands Tourist Economies"), mas com a limitação de somente se verificar em ilhas situadas na zona intertropical.

Nesta parte do texto, apenas nos referimos a alguns dos temas que assumem maior destaque no início do século XXI, no entanto, para a Geografia há sempre uma enormidade de questões com as quais poderá ser confrontada. Neste sentido, julgamos que os novos conceitos de "ilheidade", "maritimidade", "hypo-insularidade", mencionados por Vieira (2010) deverão ser alvo de debate na ciência geográfica. Por conseguinte, a Geografia, pela sua natureza, deve explorar novos temas insulares.

Mas um geógrafo nunca deverá encarar os temas insulares como um espaço apenas do âmbito da Geografia, deve procurar desenvolver trabalhos e relacionar-se de uma forma pluridisciplinar com as outras áreas disciplinares, como a Sociologia, a Antropologia, a Psicologia, a Economia, entre outras.

\section{CONSIDERAÇÕES FINAIS}

A análise efetuada permite-nos confirmar a ideia que os estudos insulares encontram-se numa fase avançada ao nível da sua consolidação. O surgimento de uma ciência das ilhas, independentemente das dúvidas ainda inerentes à mesma, nomeadamente no que concerne à sua terminologia, constituiu um marco decisivo para ascensão desta nova área do saber. No entanto, para que tal acontecesse foi fundamental o aparecimento de estruturas científicas de apoio a este tipo de investigação, principalmente em termos 
académicos, à medida que foram aumentando o número de pequenos Estados insulares. Porém, como ficou demonstrado, não foi apenas aquele grupo que desenvolveu os estudos sobre ilhas, mas também, e sobretudo, os países desenvolvidos de âmbito de insular ou predominantemente continental, mas que detém áreas insulares habitadas.

Sublinhamos a importância do papel da Geografia e do "geógrafo das ilhas" na evolução de temas insulares, na medida em que nos estudos internacionais foi possível encontrar um número significativo de geógrafos que se destacam, seja ao nível de reuniões científicas quer através de publicações. Salientamos que há áreas de estudo das ilhas que são específicas da Geografia, como por exemplo a problemática envolta dos conceitos relacionados com a definição de ilha e com a questão da insularidade, mas a área de intervenção do geógrafo é muito mais abrangente, devendo inclusive participar na elaboração dos programas de desenvolvimento das pequenas regiões insulares.

\section{REFERÊNCIAS}

BALDACCHINO, G. The Coming of Age of Island Studies. Tijdschrift voor Economische en Sociale Geographie, v. 95 , n. 3, pp. 272-283, 2004. DOI: http:// dx.doi.org/10.1111/j.1467-9663.2004.00307.x

BALDACCHINO, G. Managing the hinterland beyond two ideal-type strategies of economic development for small islands territories. Asia Pacific Viewpoint, v. 47, n.1, pp. 45 - 60, 2006a. DOI: http:// dx.doi.org/10.1111/j.1467-8373.2006.00295.x

BALDACCHINO, G. Extreme Tourism: Lessons from the world cold water. Oxford; Elsevier, 2006b, 291 p.

BALDACCHINO, G. Islands, Islands Studies, Islands Studies Journal. Islands Studies Journal, v. 1, n. 1, pp. 3-18, 2006c.

BALDACCHINO, G. Introducing a world of islands. In: BALDACCHINO, G. (Ed.). A World of Islands. Charlottetown: University of Prince Edward Island, Institute of Island Studies, 2007, p. 1-29.
BALDACCHINO, G. Studying Islands: On Whose Terms? Some Epistemological and Methodological Challenges to the Pursuit of Island Studies. Islands Studies Journal, v. 3 n. 1, pp. 37-56, 2008.

BALDACCHINO, G. Islands Enclaves. Offshoring Strategies, Creative Governance and Subnational Island Jurisdictions. Montreal; McGill-Queen`s University Press, 2010, 301 p.

BAUM, T. G. The Fascination of Islands: The Tourist Perspective. In: LOCKHART, D.; DRAKAKISSMITH, D. (Eds.). Island Tourism: Trends and Perspectives. London: Pinter, 1996, p. 21-35.

BERTRAM, G.; WATTERS, R. The MIRAB economy in the South Pacific microstates. Pacific Viewpoint, $\mathrm{v}$. 26, n. 3, pp. 497-520, 1985.

BIAGINI, E.; HOYLE, B. Insularity and Development on an Oceanic Planet. In: BIAGINI, E; HOYLE, B. (Eds.). Insularity and Development: international perspectives on islands. London; Pinter, 1999, p. 2-14.

BONNEMAISON, J. Vivre dans L'île. L'Espace Géographique, v. 19-20, n. 2, pp. 126-134, 1990-1991.

DEPRAETERE, C. Le phénomène insulaire à l'échelle du globe: tailles, hiérarchies et formes des îles océanes. L'Espace Géographique, v. 19-20, n. 2 , pp. 119-125, 1990-1991.

DEPRAETERE, C.; DAHL, A. Locations \& Classifications. BALDACCHINO, G. (Ed.). A World of Islands. Charlottetown: University of Prince Edward Island, Institute of Island Studies, 2007, p. 57-105.

DICIONÁRIO DA LÍNGUA PORTUGUESA. $D i$ cionário da Língua Portuguesa. Porto: Porto Editora, 2011.

DIEGUES, A. Ilhas e mares. Simbolismo e imaginário. São Paulo: Hucitec, 1998, 272 p.

GOUMBOUD, S. Iles, insularité et îléite. Le relativism dans l'étude des espaces archipélagiques. Dissertação 
de Doutoramento, Universidade de Reunião, 2010.

HENRIQUES, E. Distância e Conexão. Insularidade, relações culturais e sentido de lugar no espaço da Macaronésia. Angra do Heroísmo; Instituto Açoriano de Cultura e Centro de Estudos Geográficos da Universidade de Lisboa, 2009, 174 p.

KING, R. The Geographical Fascination of Islands. In: Lockhart, D.G.; Drakakis-Smith, D.; Schembri, J.A. (Eds.). The Development process in Small Islands States. London: Routledge, 1993, p 13-37.

KING, R.; CONNELL, J. Small Worlds, Global Lives: Islands and Migration. London; Pinter, 1999, 320 p.

KING, R. Islands and Migration. Insularity and Development on an Oceanic Planet. In: BIAGINI, E.; HOYLE, B. (Eds.). Insularity and Development: international perspectives on islands. London: Pinter, 1999, p. $93-115$.

KING, R. A geografia, as ilhas e as migrações numa era de mobilidade global. In: FONSECA, M. L. (Ed). Actas da Conferência Internacional - Aproximando Mundos. Emigração e Imigração em Espaços Insulares. Lisboa: Fundação Luso-Americana para o Desenvolvimento, 2010, p. 27-62.

LOCKHART, D. Introduction. In: LOCKHART, D. G.; DRAKAKIS-SMITH, D.; SCHEMBRI, J. A. (Eds.). The Development process in Small Islands States. London: Routledge, 1993, p. 1-9.

LOCKHART, D.; DRAKAKIS-SMITH, D. Island Tourism: Trends and Perspectives. London; Mansell, 1997, 320 p.

MARSHALL, J. Insiders and Outsiders: The Role of Insularity. In: KING, R.; CONNELL, J. (Eds.). Small Worlds, Global Lives: Islands and Migration. London: Pinter, 1999, p. 95-114.

MCCALL, G. Nissology: the study of Islands. Journal of the Pacific Society, v. 17, n. (2-3), pp. 1-14, 1994.
MCCALL, G. Clearing Confusion in a disembedded World: The case for Nissology. Geographische Zeitschrift, v. 84, n. 2, pp. 74-85, 1996.

MCELROY, J. Small islands tourist economies across the life cycle. Asia Pacific Viewpoint, v._47, n. 1, pp. 61-77, 2006. DOI: http://dx.doi.org/10.1111/j.14678373.2006.00303.x

MCELROY, J.; HAMMA, E. SITESs revisited: Socioeconomic and demographic contours of small islands tourist economies. Asia Pacific Viewpoint, v. 51, n. 1, 36-46, 2010. DOI : http://dx.doi.org/10.1111/j.14678373.2010.01412.x

MOLES, A. Nissologie ou science des îles. L 'Espace Géographique, v. 11, n. 4, pp. 281-289, 1982.

RIBEIRO, O. A ilha do Fogo e as suas erupções. Lisboa; Junta de Investigações do Ultramar, 1960, 319 p.

ROYLE, S. A Geography of Islands: Small Island Insularity. London; Routledge, 2001, 226 p.

ROYLE, S. Definitions \& Typologies. In: BALDACCHINO, G. (Ed.). A World of Islands. Charlottetown: University of Prince Edward Island, Institute of Island Studies, 2007, p. 33-56.

VELEZ CASTRO, F. O Eterno e o Efémero. Lisboa; Chiado Editora, 2012, 156 p.

VIEIRA, A. Repensar os Estudos Insulares Hoje. Anuário do Centro de Estudos de História do Atlântico, v. 1, pp. 16-71, 2009.

VIEIRA, A. As Ilhas: da Nissologia à Nesologia. Anuário do Centro de Estudos de História do Atlântico, v. 2, pp. 16-21, 2010.

YOUNG, L. B. Islands: Portraits of Miniature Worlds. New York: W. H. Freeman and Company, 1999, 300 p. 